\title{
Ovarian, Fallopian Tube, and Primary Peritoneal Carcinoma Clinical TNM Finding v8
}

National Cancer Institute

\section{Source}

National Cancer Institute. Ovarian, Fallopian Tube, and Primary Peritoneal Carcinoma

Clinical TNM Finding v8. NCI Thesaurus. Code C139928.

A clinical finding about one or more characteristics of ovarian, fallopian tube, or primary peritoneal carcinoma, following the rules of the TNM AJCC v8 classification system. 